\title{
Disposal of hospital wastage in Pakistan: A qualitative research
}

\author{
Syeda Zain Fatima \\ MPhil: Accounting and Finance \\ Department of: Accounting and Finance \\ University of Central Punjab Lahore \\ Dr Muzaffar Asad \\ Supervisor, MPhil: Accounting and Finance \\ Department of: Accounting and Finance \\ University of Central Punjab Lahore
}

\begin{abstract}
Background and Objective: Disposal waste process of Hospitals faced the different issues which raise the questions after the visit of government the hospitals in Punjab of Lahore. This study is used to aware about the issues about the infection wastage which cause about the different disease in Patients. This study is used to aware about the situation the government teaching hospitals of the waste management Methods: In depth interviews conducted by 3 selected hospitals of Punjab Lahore like Jinnah Hospital Lahore, Service Hospital Lahore and Mayo hospital of Lahore from respondents include Medical Superintendent, Executive Director, Deputy Director, Nursing Superintendent and Focal Medical Officer which dealing with the waste management. Results: Main gap which occur in the hospitals about the collection of the wastage and cleanliness of the hospitals. These problems occur by the less trained staff, weak monitoring and different issues which linked with the all staff members. Main results evaluate that to improve the waste management staff members in teaching hospitals of Lahore. Conclusion: The material of this study is, consequently, very essential for development and executing disposal of waste management program by any hospital. Proper distribution of budget and prearrangement of infectious waste management training at any hospital should be spelled out in health policy. A continuous supervision and monitoring could increase the motivation of health staff and ultimately affects their better working output on time.
\end{abstract}

KEYWORDS: Prearrangement of Infectious waste management, Teaching Hospital of Lahore.

\section{INTRODUCTION}

Over the past year, there is an increasing issue in public regarding waste management of health care providers. Due to increase in infection spread by hospital waste, there is increase in number of human death by waste related disease which is calculated as 5.2 million from which 4 million are children died. A good waste management can be planned by any hospital under the supervision of good administration, effectual organization and with the full interest by trained staff of hospital (WHO, 2005).Waste bags collected by housekeeping staff from all departments and separated according to their colors, and functions and storing in related room and then transferred in final storage room for further process. (CDC,1998). Hospital waste includes all the waste collected from all departments of hospital especially from Emergency, Laboratories and wards. Wastes are depends on the specialization of Hospital like PIC (Punjab Institute of cardiology) is specialized in Heart diseases. If Hospital waste not properly disposed it can be dangerous for people as well as for community. Disposing process of waste is usually assigned to untrained laborers who perform it without proper training and with inadequate preservation (Diaz et al. 2005). Hospital waste management has become a vital issue as it poses potential health risks and damage to the environment. In 2002 World Health 
Organization (WHO) reported that in 22 developing countries the proportion of healthcare facilities that did not use proper waste management was significant, ranging from $18 \%$ to $64 \%$.Epidemiological studies indicate that a person who experiences one needle-stick injury from a needle used on an infected source, patient has risks of $30 \%, 1.8 \%$, and $0.3 \%$ respectively to become infected .with HBV, HCV and HIV.

\section{Hospital Waste Management in Pakistan}

Many research have conducted on medical waste in developed and developing countries such as Jordan (Abdulla et al., 2008), Iran (Askarian et al., 2004), Egypt (Soliman and Ahmed, 2007), Mauritius (Mohee, 2005), Korea (Jang et al., 2006), Turkey (Birpinar et al., 2008), Brazil (Da Silva et al.,2005), Mongolia (Shinee et al., 2008), Greece (Tsakona et al.,2007), the USA (Lee et al., 2004), the UK (Tudor et al., 2005), and India (Patil and Shekdar, 2001).

Hospital waste management is an ever growing risk for health in developing countries like Pakistan. Its poor management has been associated with increased risk of spread of deadly infections like HCV, HBV and HIV1.

The dangerous component of hospital waste is the infectious waste that makes about $10 \%$ of total waste generated in a healthcare facility. Total healthcare waste generated in most developing countries ranges from $0.5-3 \mathrm{~kg}$ per person/ year2, while in Pakistani healthcare facilities approximately $2 \mathrm{~kg} / \mathrm{bed} /$ day waste is generated; of which $0.1-0.5 \mathrm{~kg}$ is infectious waste3, total waste generation in Punjab is $0.65 \mathrm{~kg} / \mathrm{bed} /$ day, Lahore has 44 hospitals, 500 clinics, (total bed strength 12480)4. Most contagious of hazardous hospital waste are sharps especially used syringes, infusion sets, scalpels, knives, broken glasses. Infectious waste includes dressings, clothes, used catheters, contaminated by blood and body fluids of patients, in addition, chemical, pharmacological and radiological waste is also associated with risks to the population 5.2.4 billion syringes are used in Pakistan every year. Pakistan has highest injection: patient ratio and highest rate of unnecessary injections in the world6. 30\% population is using 10 injections/person/year.

\section{LITERATURE REVIEW}

The first time introduce about medical waste management in Turkey was published in 1993, and as a candidate state, that was changed with EU Environmental Directives according with 2005. Waste is the thing that spread the germs which effects on health of patients, environment of the hospitals (H. Connor, 2008).It is to access the wastage management of the segregation of source, interim storage etc. Hospital waste caused the different diseases and infections in the patient (Toheed, Ayub, Mumtaz, \& Mehr, 2016). The medical waste management practices used by hospitals in northern Jordan. A comprehensive inspection survey was conducted for the providing information on different waste management aspects (Taghipour, et al., 2016) The hospitals focused on the medical waste segregation, treatment and disposal options practiced in the hospitals (Abdullah, Qdais, \& Rabi, 2008). Medical waste management in the light of the Medical Waste Control Regulation (MWCR) in Istanbul, the largest city in Turkey. A candidate state, it was changed in 2005 in accordance with EU Environmental Directives (Toheed, Ayub, Mumtaz, \& Mehr, 2016) (Birpinar , Biligili, \& Erdogan, 2009). Medical waste generated in healthcare facilities (HCFs) were conducted in to existing both waste collection and disposal approaches, these approaches used for improvement of sustainable avenues for institutional policy. Management practices expose the more facilities of the patients, staff, waste handlers and the populace to unnecessary health risks (Kumar, Somrongthong, \& Shaikh, 2015). The researcher proffers recommended to need for sustaining the cooperation among all key actors (government, hospitals and waste managers) for implementing a safe and reliable medical waste management strategy, not only 
in legislation and policy formation but also particularly in its monitoring and enforcement and obligation for each HCF to ensure about the safe and hygienic system of medical waste handling, segregation, collection, storage, transportation, treatment and disposal, with minimal risk to handlers, public health and the environment (Coker, et al., 2009), (Ferreira \& Teixeira, 2010). Medical waste management has great importance due to its infectious and hazardous nature which can cause undesirable effects on humans and the environment (A \& C, 2010).Waste management analyzes and evaluates the status of medical waste management in the light of medical waste control regulations in Nanjing (Yong, Gang, Guanxing, Tao, \& Dawei, 2009). The Private Medical Microbiology Laboratories (PMML) produced the generation rate and composition of the solid medical waste and was conducted in Greece. Such information existed in the literature for this type of laboratories worldwide (Komilis, Makroleivaditis, \& Nikolakopoulou, 2017). A wider range of people and organizations had paid to increase the potential harm from medical waste (Janjua NZ, 2003). Hospitals of medical waste management can be improved by the Medical Waste-generations assessment. That could be used for planning, budgeting, cost controlling, and optimizing waste-management systems $(\mathrm{Q}, \mathrm{H}, \mathrm{Y}, \mathrm{SR}$, $\& Y, 2005)$. It also provided that opportunity to compare with other hospitals. Because medical waste-generation rate is not a homogeneous indicator without considering the differences of the hospital's scale, type, specialization, technical level, quality, and efficiency, people cannot simply use the generation rate to compare performance between hospitals (Xin, 2015). According to the Brazilian law, implementation of a Medical Waste Management Plan (MWMP) in health-care units is mandatory, but evaluate the implementation had not taken place yet (Rao PH, 2008). The purpose of evaluation is deriving to improve the implementation of MWMP in a Primary Health-care Center (A.M.M.Moreiar \& W.M.R.Gunther, 20013). Health-care facilities were grouped into public and private ones, and, also, into seven sub-categories, namely: birth, cancer treatment, general, military, pediatric, psychiatric and university hospitals. There is a large variability in the HMWUGR, even among hospitals of the same category. Based on non-parametric statistics, HMWUGR were statistically similar for the birth and general hospitals, in both the public and private sector. The private birth and general hospitals generated statistically more wastes compared to the corresponding public hospitals (Komilis, Fouki, \& Papadopoulos, 2012). Challenges of infection of waste and management for practicesing in teaching hospitals in Pakistan. Serious gaps and deficiencies were observed related to segregation, collection, storage and disposal of the hospital wastes, hence proving to be hazardous to the patients as well as the visitors (Qaiser S, 2012), (Harhay MO, Halpern SD, Harhay JS, \& Olliaro PL, 2009). Poor safety, insufficient budget, lack of trainings, weak monitoring and supervision, and poor coordination has eventually resulted in improper waste management in the tertiary hospitals of Rawalpindi (Kumar, Shaikh, Somrongthong, \& Chapman, 2015 ). As nursing and paramedical staff was more knowledgeable and practiced optimum standards they needed to be rewarded adequately and given further regular trainings to help them maintain their knowledge and best practices about HCWM. As HCWM and patient safety standards keep on changing regularly, the hospital workers especially doctors need to be focused to comply with the standard practices in hospitals (Kumar, Somrongthong, \& Ahmed, 2016). The 7-S technique played main role in the assessment of the hospital waste management system. Training main role in the healthcare workers which played the significant role in the healthcare facilities (Ullah, Ahmed, Malik, \& Khan, 2011).Hospital disposal of waste had poor practice in the hospitals if the management would not improve much threats for humans and environmental healths occure (Qadir, et al., 2014). Family of medicins rotation is the part of the post graduate medical gives the help for predicting the interest with the medical students which effect the quality of the health care (P. Iqbal , 2010). The standard in the tertiary care hospitals of Pakistan which follows the WHO rules (Kumar, Samrongthong, \& Shaikh, 2013). Hospitals are the main area of hazardous waste which transfer local area (Aljabre, 2002). However gap is also exist in this research doctors or waste management staf 
members do not work properly in the hospitles. Used injections and other surgical tools used with other patients which cause the different disease in the patients. Its needs to explore more for the better implementation about the wastage of the hospitals.

\section{METHODS}

It was a qualitative descriptive study with cross sectional design. Qualitative approach used in the semi structured questionnaire interview which conducted questionnaires for in-depth interviews was carried out, using validated WHO checklist for segregation, collection, storage and disposal of infectious waste. All departments of the hospitals were included. In addition, in-depth interviews were conducted till the point of saturation. Principal investigator himself conducted six in-depth interviews, using WHO semi-structured questionnaire, after taking the appointment and written consent. Respondents included the Medical Superintendent, Executive Director, Deputy Director, Nursing Superintendent and a Focal Medical Officer, dealing with the waste management. Verbatim notes were taken and interviews were recorded, with permission. Specific nodes were developed for the questions, and significant findings and responses were aggregated as sub nodes, which were later developed into themes. Information from literature and responses were then triangulated in the discussion section. Ethical consideration: Ethics approval for this study was granted by the Institutional Review Board of Health Services Academy, Islamabad Pakistan. Verbal informed consent was obtained from all the administration staff of 3 teaching hospitals like Jinnah Hospital Lahore, Service Hospital Lahore and Mayo hospital of Lahore which are regulate under the Govt. rules and regulation, after explaining the objectives of the study. Confidentiality and anonymity was assured to all the participants. Data was kept under lock and key with the principal researcher.

\section{RESULTS}

This section is completely explains the result that is made on the basis of interviews which interviews was conducted three hospitals of Lahore. Respondents included female and male staff, regular government employees who were overseeing the management of infectious waste as Medical Superintendent, Executive Director, Deputy Director, Nursing superintendent and a focal medical officer. The several Questions were asked to the management of different hospitals. The question was asked that do you know about the medical waste and its categories. The management of these hospitals said that the autoclave and three chamber incinerators were used for the final disposal of the infectious waste. However, there is no back up for both the machines. The other question was asked that are you satisfied with the medical waste management in Lahore. Most of the management answered that they are not satisfied about the waste because these waste are used by some companies to make different plastic product that was harmful to the humans.

In most hospitals, there are not at all special drays or special directions to transference the waste. The strips and the commuters' winches are used. Henceforth, patients, visitors and workers could be imperiled to health dangers. Twenty five percent of the infirmaries have no storing facilities and usage the same ampules which are situated in the thoroughfares devoted for municipal waste. Most of these ampules have no defense against faunae (EQA, 2005).

On the further pointer investment in the exercise of these workforces will be valuable as it is predictable they will stay in their work for reasonable period. Also it will be very helpful to keep the trained workers by giving them good work atmosphere and conditions. The danger that the worker may be subjected to when dealing with medical waste will decrease as the experience of the worker increases. 


\section{CONCLUSION}

In interpreting the results of this research, it is essential to identify its boundaries. The sample mass was small and derived from Management who had already participated in a study of physical activity in disposal of waste management and thus may have already been interested to maintain a waste management. The applicants were also comparatively well sophisticated with a high level of employment. This study also supports us to distinguish how much return any waste management company or agency might expect from wards. The material of this study is, consequently, very essential for development and executing disposal of waste management program by any hospital. Moreover, along with the enhancement of overall cleanliness and disposal facilities, the present study will also fascinate the devotion of the policy-maker who may be observing to increase the disposal service. Proper distribution of budget and prearrangement of infectious waste management training at any hospital should be spelled out in health policy. A continuous supervision and monitoring could increase the motivation of health staff and ultimately affects their better working output on time

\section{References}

A, B., \& C, T. (2010). Health care waste management of potentially infectious medical waste by healthcare professionals in a private medical practice: a study of practices. PubMed, 22(6), 605-15.

A.M.M.Moreiar, \& W.M.R.Gunther. (20013, January). Assessment of medical waste management at a primary health-care in Sao Paulo, Brazil. Waste Management, 33(1), 162-167.

Abdulllah, F., Qdais, H. A., \& Rabi, A. (2008). Site investigation on medical waste management practices in North Jorden. ELSEVIER, 28(2), 450-458.

Aljabre, S. H. (2002, August). Hospital genrated waste: A plan for its proper management. Journal of Family \& Community Medicine, 9(2), 61-65.

Birpinar , M. E., Biligili, S. M., \& Erdogan, T. (2009, January). Medical waste management in Turkey: A case study of Istanboul. ELSEVIER, 29(1), 445-448.

Coker, A., Sangodoyin, A., Sridhar, M., Booth, C., Olomolaiye, P., \& Hammond, F. (2009, February). Medical waste management in Ibadan, Nigeria: Obstacles and prospects. Waste Management, 29(2), 804-811.

Ferreira, V., \& Teixeira, M. R. (2010). Assessing the medical waste management practices and associated risk perceptions in Algarve hospitals, Portugal. Waste Management, 30(26), 57-63.

H. Connor, T. (2008). Preventing occupational exposures to antineoplastic drugs in health care settings. A Cancer Journal for Clinicians, 56(6), 354-365.

Harhay MO, Halpern SD, Harhay JS, \& Olliaro PL. (2009, November). Health care waste management: A neglected and growing public health problem worldwide. PubMed, 14(11), 1414-7.

Janjua NZ. (2003, March). Injection practices and sharp waste disposal by general practitioners of Murree, Pakistan. PubMed, 53(3), 107-11.

Komilis, D., Fouki, A., \& Papadopoulos, D. (2012, July). Hazardous medical waste generation rates of different categories of health-care facilities. Waste Management, 32(7), 1434-1441.

Komilis, D., Makroleivaditis, N., \& Nikolakopoulou, E. (2017, March). Generation and composition of medical wastes from private mendical microbiology liboraties. Waste Management, 61(1), 539-546.

Kumar, R., Samrongthong, R., \& Shaikh, B. T. (2013). Knowledge, attitude and practices of health staff regarding infectious waste handling of tertiary care health facilities at metropolitan city of Pakistan. J Ayub Med Coll Abbottabad, 25(1-2), 109-112.

Kumar, R., Shaikh, B. T., Somrongthong, R., \& Chapman, R. S. (2015 ). Practices and challenges of infectious waste management: A qualitative descriptive study from tertiary care hospitals in Pakistan . PakJ Med Sci, 31(4), 795798.

Kumar, R., Somrongthong, R., \& Ahmed, J. (2016). EFFECT OF MEDICAL WASTE MANAGEMENT TRAININGS ON BEHAVIOR CHANGE AMONG DOCTORS VERSUS NURSES AND PARAMEDICAL STAFF IN PAKISTAN. J Ayub Med Coll Abbottabad, 28(3), 393-496. 
Kumar, R., Somrongthong, R., \& Shaikh, B. T. (2015). Effectiveness of intensive healthcare waste management training model among health professionals at teaching hospitals of Pakistan: a quasi-experimental study. $B M C$ Health Serv Research, 81(15), 1-8.

P. Iqbal , S. (2010). Family medicine in undergaduate medical curricullum: A cost-effective approach to health care in Pakistan. J Ayub Med Coll Abbottabad, 22(4), 207-209.

Q, A., H, S., Y, A., SR, R., \& Y, U. (2005). Knowledge of students regarding hepatitis and HIV/AIDS of a private medical university in Karachi. PubMed, 55(7), 285-8.

Qadir, S., Akhtar, M. N., Hassan, M. U., Ahmad, I., Naeem, H., \& Rehman, O. U. (2014, April-June). Study of hospital waste disposal practice in a tertiary care hospital. Gomal Journal of Medical Sciences, 12(2), 64-67.

Qaiser S. (2012, February). Survey of sharp waste disposal system in clinics of New Karachi. PubMed, 62(2), $163-4$.

Rao PH. (2008, Jun). Report: Hospital waste management--awareness and practices: a study of three states in India. PubMed, 26(3), 297-303.

Taghipour, H., Alizadeh, M., Dehghanzadeh, R., Farshchian, M. R., Ganbari, M., \& Shakerkhatibi, M. (2016). Performance of on-site medical waste disinfection equipment in. Health Promotion Perspectives, 6(4), $202-206$.

Toheed, R., Ayub, T. B., Mumtaz, S., \& Mehr, A. R. (2016, JUNE). Hospital waste management in teaching hospitals system assessment using new tool. PJMHS, 10(2), 379.

Ullah, J. H., Ahmed, R., Malik, J. I., \& Khan, M. (2011). Outcome of 7-S, TQM technique for Healthcare Waste Management. Journal of the College of Physicians and Surgeons Pakistan, 21(12), 731-734.

Xin, Y. (2015, August). Comparison of hospital medical waste generation rate based on diagnosis-related groups. Journal of Clearner Production, 100(1), 202-207.

Yong, Z., Gang, X., Guanxing, W., Tao, Z., \& Dawei, J. (2009, April). Medical waste management in China: A case study of Nanjing. Waste Management, 29(4), 1376-1382. 